\title{
A queixa escolar em um CAPSi de Salvador-Bahia: uma análise a partir da psicologia escolar crítica
}

\author{
Klessyo do Espirito Santo Freire \\ Lygia de Sousa Viégas \\ Universidade Federal da Bahia
}

\section{Resumo}

presente trabalho objetiva analisar de que maneira as queixas escolares são entendidas e atendidas em um Centro de Atenção Psicossocial de Salvador-Bahia, considerando suas relações com o fracasso escolar e a medicalização da educação. Para tanto, foi realizada uma pesquisa qualitativa e quantitativa de fundamentação etnográfica em um CAPSi (Centro de Atenção Psicossocial Infanto-Juvenil) de Salvador-Bahia, utilizando como recursos metodológicos análise de prontuários, observação participante e entrevista com profissionais. $\bigcirc$ referencial teórico adotado foi a Psicologia escolar e educacional em uma perspectiva crítica. Os resultados apontaram que a queixa escolar estava presente em 55\% dos pacientes atendidos. Foi encontrado que a maneira predominante de entendimento e atendimento da mesma partiu de uma perspectiva individualizante e medicalizante, advinda de um modelo clínico tradicional. Conclui-se com a necessidade de aprofundar o debate da temática do fracasso escolar e da medicalização da educação e da pobreza na formação básica e continuada de profissionais da

Palavras-chave: Fracasso escolar. Medicalização. Psicologia escolar.

\section{School complaints at a CAPSi in Salvador-Bahia: an analysis from a critical school psychology point of view}

\section{Abstract}

Present study objectives analysis how the school complaint are understood and met in a Psychosocial Attention Centre in Salvador - Bahia considering the relation with the school fail and medicalization of education. For this purpose was implementing a qualitative and quantitative research of ethnographic reason in the CAPSI (Center for Psychosocial Child and Adolescent Care) of Salvador - Bahia, using as methodological resources, files analyses, participant observation and interviews with profissionals. The theoretical reference adopted was the school and educational psychology in a critical perspective. Results indicate that 55\% of the patients present school complaints. In this way it was observed that the prevailing way of understading and attendance of the complaint began from a individual and medicalazition perspective. It concludes there is need to improve this discussion about school fail, education medicalization of education and failure in the training in basic and continuated education in healthcare profissionals.

Keywords: School fail. Medicalization. School psychologist. 


\section{La queja escolar en un CAPSi de Salvador-Bahia: un análisis a partir de la psicología escolar crítica}

\section{Resumen}

El presente estudio analiza en que manera son comprendidas y atendidas la queja escolar en el Centro de Atención Psicosocial de Salvador-Bahia, considerando las relaciones entre fracaso escolar y medicalización de la educación. Para ello fue realizada una pesquisa cualitativa y cuantitativa sobre la fundamentación etnográfica en un CAPSI (Centro de Atención Psicosocial Infanto-Juvenil) de Salvador-Bahia, con el uso de técnicas tales como: análisis de los registros médicos, observación participante, entrevista con profesionales. El referencial teórico adoptado está relacionado con la Psicologia Escolar y Educacional desde una perspectiva crítica. Los resultados apuntaron que la queja escolar representa un 55\% de los pacientes atendidos. Además fue determinado que la manera predominante sobre la comprensión y atendimiento de las misma parten desde una perspectiva individualizante y medicalizante, derivada de un modelo clínico tradicional. Se concluye que se debe profundizar en el debate de la temática acerca del fracaso escolar y su relación con medicalización de la educación derivada a su vez de la formación básica y continua del personal de salud.

Palabras clave: Fracaso escolar. Medicalización. Psicologia escolar.

\section{Introdução}

Presente artigo teve como objetivo analisar de que maneira as queixas escolares são entendidas e atendidas em um Centro de Atenção Psicossocial Infanto-juvenil (CAPSi) de Salvador-Bahia, considerando suas relações com o fracasso escolar e a medicalização da educação.

Historicamente a educação brasileira, sobretudo a pública, tem sido marcada pelo descaso e a precariedade. Desde o princípio, o estado brasileiro tem se caracterizado pelo fracasso em atingir planos e metas traçados pelas plataformas governamentais, expressando-se em uma grande quantidade de alunas e alunos com dificuldades no processo de escolarização. A expressão "fracasso escolar" tem sido utilizada recorrentemente para denominar esse problema crônico (PATTO, 1999).

Essa discussão tem tomado relevância desde os anos 1980 na Psicologia Escolar e Educacional e na Educação, sobretudo com os trabalhos da pesquisadora Maria Helena Souza Patto (1984; 1999), marcando uma ruptura na forma de compreender o fracasso escolar no Brasil. A partir dos escritos 
A queixa escolar em um CAPSi de Salvador-Bahia: uma análise a partir da psicologia escolar crítica

da autora, esse fenômeno passou a ser analisado a partir do contexto histórico, político, econômico e social, além de aspectos institucionais, pedagógicos e relacionais nele envolvidos.

À luz do materialismo histórico-dialético, a autora analisou as raízes históricas das explicações hegemônicas sobre o fracasso escolar que estão presentes no cotidiano das instituições educacionais brasileiras, sobretudo as públicas. Assim, seja por supostos déficits biológicos ou por supostas carências culturais advindas da condição de pobreza, a autora constatou que a gênese dessas explicações é sempre a mesma: a culpabilização do indivíduo, ou seja, atribui-se as desigualdades sociais à supostas diferenças individuais de capacidade. Elas partem de uma ideologia liberal que desconsidera as diversas desigualdades (de gênero, classe, religiosa etc.) que estão presentes no bojo de uma sociedade capitalista dividida em classes (PATTO, 1984; 1999).

Portanto, a partir das pesquisas de Patto, um coletivo de psicólogas/ os passou a analisar a escola em suas dimensões histórica, política e econômica. De acordo com Souza (2007, p. 242), "[...] a escola, como ocorre com as instituições em geral, é um campo de contradições e paradoxos. Nela atuam forças que tendem a produzir fracasso e sofrimento nas pessoas que 204 dela fazem parte".

Atrelado ao fracasso escolar, tem ocorrido o fenômeno denominado por diversos pesquisadores como medicalização da educação e da sociedade. Primeiramente, cabe caracterizar o termo medicalização. Identifica-se que este surgiu no final da década de 1960 e teve como precursor e filósofo austríaco Ivan Illich, destacadamente com os livros A expropriação da saúde: nêmesis da Medicina (1975) e Sociedade sem escolas (1985). Outro importante autor que contribuiu com a discussão foi Foucault, que, mesmo não fazendo uso sistemático do termo, trouxe pontos importantes com o conceito de biopoder (GAUDENZI; ORTEGA, 2012).

Os autores identificam que as raízes históricas do processo de medicalização datam do final do século XVII, com o nascimento da medicina moderna e da higiene. A medicina passou a intervir no corpo social, estabelecendo o que é normal e o que é doença, produzindo saberes alicerçados em normas morais de condutas e prescrições de comportamento, tornando as pessoas dependentes de especialistas para cuidar da sua saúde. No Brasil, destacam-se os trabalhos da psicóloga Patto, da pedagoga Cecília Collares 
e da pediatra Maria Aparecida Affonso Moysés, que incorporaram a análise da medicalização no campo da educação (GAUDENZI; ORTEGA, 2012; FÓRUM..., 2013; VIÉGAS; FREIRE, 2015).

Diante da polissemia do conceito, neste trabalho adota-se aquele definido pelo Fórum sobre Medicalização da Educação e da Sociedade, publicado na Carta do IV Seminário Internacional A educação medicalizada: desver o mundo, perturbar os sentidos:

Medicalização envolve um tipo de racionalidade determinista que desconsidera a complexidade da vida humana, reduzindo-a a questões de cunho individual, seja em seu aspecto orgânico, seja em seu aspecto psíquico, seja em uma leitura restrita e naturalizada dos aspectos sociais. Nessa concepção, características comportamentais são tomadas apenas a partir da perspectiva do indivíduo isolado, que passaria a ser o único responsável por sua inadaptação às normas e padrões sociais dominantes. A medicalização é terreno fértil para os fenômenos da patologização, da psiquiatrização, da psicologização e da criminalização das diferenças e da pobreza (FÓRUM..., 2015, p. 1).

No campo da educação, a medicalização tem se expressado na transformação de problemas educacionais, advindos de uma escola que historicamente produz fracasso escolar, em doenças e transtornos que têm de ser resolvidos pelos profissionais de saúde, com destaque para a medicina. Cria-se, assim, uma demanda por esses profissionais, gerando uma cultura de encaminhamento nas instituições escolares. Atualmente, a medicalização da educação assume a sua face mais determinista e biologicista, a patologização, caracterizando o que Collares e Moysés (2014) denominam de "educação na era dos transtornos".

No bojo dessas concepções, encontram-se diversos preconceitos raciais sobre a inferioridade dos negros e do povo brasileiro, já que a mestiçagem era considerada produtora de uma classe trabalhadora inferior do ponto de vista intelectual e biológico. Como resultado, acontece a medicalização do fracasso escolar, em que dificuldades no processo de escolarização são vistas como transtornos inerentes ao indivíduo, necessitando de diagnóstico e tratamento nos serviços de saúde. Trata-se de uma visão reducionista e naturalizada da aprendizagem, do desenvolvimento humano e do processo de escolarização, que é complexo e envolve todo um contexto histórico, político, econômico 
A queixa escolar em um CAPSi de Salvador-Bahia: uma análise a partir da psicologia escolar crítica

e social, além de aspectos institucionais, pedagógicos e relacionais (PATTO, 1999; COLLARES, MOYSÉS, 2014; VIÉGAS, 2014).

Para Viégas, verifica-se que:

Neste ponto, o sistema educacional encontra-se de forma perversa com as políticas de saúde. A equação é quase simples: na medida em que a escola é precarizada pelas políticas educacionais, implantadas com vistas ao barateamento dos investimentos públicos, aumenta o fracasso escolar, que, interpretado como problema biológico, amplia a demanda por projetos de 'saúde do escolar' (VIÉGAS, 2014, p. 129).

Entre os serviços de saúde que têm recebido encaminhamento de queixas escolares, destacam-se os de saúde mental, em especial os CAPSi. Um conjunto de trabalhos tem encontrado esse tipo de demanda no cotidiano dos serviços, apontando que, em muitos deles, ela representa a maioria dos casos encaminhados e atendidos (BORDINI, GADELHA, PAULA, BRESSAN, 2012; BELTRAME, BOARINI, 2013 ; BRAGA, JESUS, 2013; VIÉGAS, 2014a).

O CAPSi preconiza um modelo de atenção e cuidado de cunho comu-

206 nitário e psicossocial para crianças e adolescentes em sofrimento psíquico grave e moderado. Fruto da reforma psiquiátrica e da luta antimanicomial, esse serviço é resultado da política de saúde mental para crianças e adolescentes, criada recentemente com a Lei $n^{\circ} 10.216$, de 6 de abril de 2001, que reorientou o modelo de atenção em saúde mental; e a Portaria GM/MS n 336, de 19 de fevereiro de 2002, que regulamentou a ação dos CAPS para as/os adultas/os e para a infância e adolescência.

O CAPSi é definido como:

[...] um serviço de atenção diária destinado ao atendimento de crianças e adolescentes gravemente comprometidas psiquicamente. Estão incluídos nessa categoria os portadores de autismo, psicoses, neuroses graves e todos aqueles que, por sua condição psíquica, estão impossibilitados de manter ou estabelecer laços sociais. A experiência acumulada em serviços que já funcionavam segundo a lógica da atenção diária indica que se ampliam as possibilidades do tratamento para crianças e adolescentes quando o atendimento tem início o mais cedo possível, devendo, portanto, os CAPSi estabelecerem as parcerias necessárias com a rede de 
saúde, educação e assistência social ligadas ao cuidado da população infanto-juvenil (BRASIL, 2004, p. 23).

mesmo documento diz que as atividades do CAPSi

[...] devem ser dirigidas para a faixa etária a quem se destina atender. Assim, por exemplo, as atividades de inserção social devem privilegiar aquelas relacionadas à escola. (BRASIL, 2004, p. 23)

Couto (2012) assinala que o CAPSi pode ser considerado a primeira política sistemática de saúde mental na infância e adolescência, frisando que, anteriormente, a atenção a esse público era incipiente e marcada pela institucionalização, sendo que em muitos casos ocorria junto com as/os adultas/os.

Apesar de a política preconizar um tratamento de cunho psicossocial e multidisciplinar, na prática pesquisadores têm encontrado que os CAPSi e as instituições de saúde mental na infância e adolescência têm atendido a queixa escolar a partir de uma lógica ambulatorial advinda de um modelo clínico tradicional (CABRAL, SAWAIA, 2001 ; MARCAL, SILVA, 2006; BELTRAME, BOARINI, 2013; SOUZA, BRAGA, 2014; LIMA, 2016).

Beltrame e Boarini (2013) pontuam que, na lógica ambulatorial, o CAPSi é visto como um lugar em que as crianças são encaminhadas para receber diagnóstico e tratamento, coadunando com o modelo tradicional de atendimento à queixa escolar. Nele, o contexto da escola não é levado em conta e a atuação centra-se na avaliação e trabalho psicopedagógico, tendo como foco a compensação de "[...] supostas defasagens cognitivas, a eliminação de comportamentos inadequados e o tratamento de supostos problemas emocionais" (CABRAL; SAWAIA, 2001, p. 152).

Segundo Souza, o modelo tradicional de atender e compreender a queixa escolar é:

Reflexo de uma visão de mundo que explica a realidade a partir de estruturas psíquicas e nega as influências e/ou determinações das relações sociais sobre o psiquismo, encobrindo arbitrariedades, os estereótipos e preconceitos de que as crianças de classes populares são vítimas no processo educacional e social (SOUZA, 2010, p. 351. 
A queixa escolar em um CAPSi de Salvador-Bahia: uma análise a partir da psicologia escolar crítica

A partir das críticas realizadas ao modelo tradicional surgiram novas maneiras de atendimento à queixa escolar, que a consideram como um fenômeno complexo e multifatorial no qual estão envolvidos aspectos relacionados ao contexto histórico, político, econômico, social, institucional, pedagógico e relacional. O cenário principal em que ela emerge e é sustentada é o universo escolar e seu cerne é o processo de escolarização. Como exemplo desse tipo de atuação, cita-se os trabalhos da psicóloga Beatriz de Paula Souza (2007b), Maria Cristina Machado Kupfer (2010) e Adriana Marcondes Machado (201 1), bem como as Recomendações de práticas não medicalizantes para profissionais e serviços de educação e saúde (FÓRUM, 2013).

A partir dessas constatações, a presente pesquisa partiu da necessidade de investigar como as queixas escolares têm sido acolhidas e atendidas nos CAPSi, levando em conta o fracasso escolar e a medicalização da educação. Ela torna-se mais importante devido à pesquisa realizada por Viégas (2014a), que investigou as práticas e concepções no campo educacional e público na Bahia. Tal pesquisa encontrou que quase não existem psicólogos atuando na rede pública de ensino, indicando que as queixas escolares estavam sendo encaminhadas para serviços de saúde mental e assistência social, 208 com destaque para o CAPSi. Essa realidade aumenta a importância de se investigar tal questão na Bahia e na cidade de Salvador.

É expectativa da pesquisa contribuir para a construção da atual política de saúde mental na infância e adolescência e no atendimento à queixa escolar nos seus serviços, comprometida com uma educação de qualidade para todas e todos.

\section{Método}

Primeiramente, esta pesquisa foi aprovada pelo Comitê de Ética da Escola de Enfermagem da Universidade Federal da Bahia com o número 1. 182.045 e o CAAE 48087715.4.0000.5531. Ela seguiu todos os parâmetros de eticidade indicados na Resolução 466/2012, do Conselho Nacional de Saúde.

A abordagem teórico-metodológica utilizada foi a pesquisa qualitativa e, nela, o estudo de caso de fundamentação etnográfica. A escolha da abordagem qualitativa de fundamentação etnográfica se deu pois, segundo lüdke 
e André (1986) e Gonzaga (2006), ela traz a possibilidade de apreender os significados sociais e subjetivos relacionados aos fenômenos estudados, propiciando uma compreensão da relação do indivíduo com a cultura. Além disso, Rockwell (1986) e Macedo (2000) apontam que o método de fundamentação etnográfica viabiliza documentar o não documentado, lançando luz ao fazer diário do fenômeno pesquisado, nesse caso as queixas escolares que chegam em um CAPSi de Salvador-Bahia.

A pesquisa de campo ocorreu no período entre outubro de 2015 e abril de 2016, quando o pesquisador frequentou o CAPSi pesquisado semanalmente, a fim de estabelecer uma relação de confiança com as/os profissionais, usuários e familiares. Como procedimentos metodológicos, foram adotados o levantamento de prontuários, a observação participante e a entrevista semidirigida.

Com o objetivo de traçar um perfil dos usuários atendidos em um CAPSi, com destaque para aqueles que possuem queixa escolar, foi feito um levantamento dos prontuários do CAPSi no período de novembro 2015 à janeiro de 2016, referente à realização da pesquisa. Como critério de exclusão e inclusão, foram acessados apenas os prontuários daqueles que, efetivamente, passaram a ser atendidos na instituição, desconsiderando, portanto, os casos que, após o acolhimento, foram finalizados ou encaminhados à outras instituições. Esse procedimento foi adotado devido à dificuldade de acessar esses prontuários, pois não eram colocados no armário em que deveriam ser guardados e ficavam "perdidos" na instituição, impossibilitando ao pesquisador ter contato com eles e incluílos no levantamento. Os prontuários foram analisados a partir dos seguintes critérios: idade, gênero, escolaridade quando encaminhado ao CAPSi, ano de admissão no CAPSi, quem realizou o encaminhamento para o CAPSi, as queixas que resultaram no encaminhamento ao CAPSi, diagnóstico psiquiátrico atual e se recebe algum benefício do governo. Esse material serviu para levantar a natureza das queixas e encaminhamentos, identificando a sua proporção em relação aos atendimentos da instituição.

Visando compreender qual a perspectiva de profissionais sobre a queixa escolar encaminhada para o CAPSi e analisar como a queixa escolar é acolhida e atendida em um CAPSi, foram realizadas observações participantes e entrevistas semidirigidas. 
A queixa escolar em um CAPSi de Salvador-Bahia: uma análise a partir da psicologia escolar crítica

A observação participante ocorreu no período entre dezembro de 2015 e abril de 2016, abrangendo, sobretudo, as seguintes situações: quatro acolhimentos, dois atendimentos, duas visitas às escolas, 11 encontros do grupo de adolescentes, uma reunião de equipe, uma conversa com uma mãe de uma criança atendida na instituição e uma reunião com o Ministério Público. Cada observação foi registrada em um diário de campo e, posteriormente, no prazo máximo de 48 horas após a sua ocorrência, foram feitos relatos ampliados com uma descrição densa e detalhada das situações vivenciadas nos diários de campo (ROCKWELL, 1988). No que tange às entrevistas semidirigidas, elas foram realizadas com três profissionais do CAPSi que atendem de forma mais direta as queixas escolares na instituição.

A análise do material construído na pesquisa de campo foi realizada de forma qualitativa e quantitativa. No que se refere aos prontuários, também foi feita uma análise qualitativa e quantitativa. Já em relação ao material obtido nos relatos ampliados e nas entrevistas semidirigidas, foi feita uma análise qualitativa de acordo com as diretrizes da etnografia (MACEDO, 2000; VIÉGAS, 2007) e a "estratégia de retardamento da categorização", presente em Michell Thiollent (1980), no intuito de evitar a imposição da problemática e a catego210 rização antecipada do material obtido. Assim, através da impregnação do material obtido nos relatos ampliados e nas entrevistas, sendo lidas e relidas várias vezes, as categorias de análise foram construídas de acordo com a teoria e o que está expresso nas entrevistas e observações.

Para a articulação da análise dos diferentes procedimentos de campo, levou-se em consideração o que Minayo (2014) chama de triangulação, propondo uma abordagem transdisciplinar que supera a dicotomia de pesquisa qualitativa versus pesquisa quantitativa. A partir de uma perspectiva qualitativa, a análise centrou-se no fazer do dia a dia do CAPSi em relação às queixas escolares, buscando a compreensão de como elas são entendidas e atendidas no equipamento.

\section{Resultados e discussão}

A seguir, serão apresentados os principais resultados encontrados na pesquisa. 


\section{Análise dos prontuários}

Foram acessados 283 prontuários de pacientes que estavam sendo atendidos no equipamento no período entre dezembro de 2015 e abril de 2016. A partir do levantamento realizado, identificou-se que os usuários atendidos no CAPSi pesquisado são na maior parte meninos (70\%), com média de idade de 12,22 anos, que estudam nos primeiros anos do Ensino Fundamental e com uma condição socioeconômica de pobreza ou de extrema pobreza. Eles/as têm chegado ao CAPSi através de demanda espontânea, majoritariamente, ou encaminhados de instituições de saúde, sendo que a maior prevalência dos transtornos psiquiátricos tem sido o retardo mental (19\%) e o transtorno do espectro autista (14,3\%). A idade, quando encaminhados, foi de 9,61 anos. Verificou-se também que o tempo que as crianças e adolescentes estavam sendo atendidas no CAPSi é de 2,3 anos.

No que tange às crianças e adolescentes que possuíam queixa escolar, elas estiveram presentes em 156 casos (55\%), o que representa a maioria dos atendimentos realizados no equipamento. Esses números coadunam com outros trabalhos realizados sobre a temática, apontando que este tipo de demanda tem sido predominante nos CAPSi. Nos trabalhos realizados por Bordini, Gadelha, Paula e Bressan (2012), Beltrame e Boarini (2013) e Braga e Jesus (2013) em equipamentos similares ao dessa pesquisa, também foi encontrado que a queixa escolar representava a maior parte dos casos atendidos.

Portanto, a partir do levantamento dos prontuários, indica-se o seguinte perfil das/os usuárias/os atendidas/os com queixa escolar: são majoritariamente do gênero masculino e com média de idade de 12 anos; a média de idade quando encaminhados era de 9,61 anos e se encontravam, em sua maioria, na Educação Infantil e no Ensino Fundamental l; a origem dos encaminhamentos se concentrou por demanda espontânea e das áreas de educação e saúde. No que tange a prevalência dos diagnósticos psiquiátricos, foi encontrado o retardo mental ${ }^{1}(18,4 \%)$, o transtorno do espectro autista $(11,9 \%)$ e o transtorno do déficit de atenção e hiperatividade $(6,5 \%)^{2}$, o popular TDAH. Destaca-se que o retardo mental e o TDAH são categorias diagnósticas que têm sido utilizadas historicamente para medicalizar crianças e adolescentes em situação de fracasso escolar, como aponta pesquisadoras/es como Kalmus (2000), Lima (2005;2014), Viégas e Oliveira, (2014) e Gould (2014). 
A queixa escolar em um CAPSi de Salvador-Bahia: uma análise a partir da psicologia escolar crítica

Verifica-se, também, que a maioria das crianças encaminhadas concentra-se nos anos iniciais de escolarização. Nesse período, elas estão nos primeiros anos de apropriação da leitura e escrita, sugerindo que questões de escolarização, relativas ao letramento, podem estar sendo considerados transtornos que devem ser encaminhados aos serviços de saúde, resultado semelhante ao encontrado nos trabalhos de Beltrame e Boarini (2013) e Souza e Braga (2014).

\section{Análise dos relatos ampliados}

A análise dos relatos ampliados produzidos a partir das observações participantes teve como finalidade compreender como a queixa escolar é acoIhida e atendida em um CAPSi.

Primeiramente, cumpre ressaltar as dificuldades de estrutura vivenciadas pelas/os profissionais, a começar pelo fato de que em Salvador, uma cidade com quase três milhões de habitantes, existem somente dois CAPSi. A falta de salas, salas sem estrutura, falta de materiais, falta de carro para as visitas, a sobrecarga de trabalho, a falta de locais na rede para encaminhar

212 e um território enorme para dar conta geravam um grande desgaste físico e psíquico nas/os profissionais, como pode ser visto na seguinte afirmação de uma delas: "Tem que tomar cuidado, senão o CAPS te engole. É tanta coisa que se for parar para pensar nelas... A saúde mental não dá lucro para o SUS" (PARTICIPANTE DA PESQUISA 1, 2015).

Essas/esses profissionais convivem diariamente com obstáculos objetivos para a realização de um trabalho com a complexidade que essas instituições demandam, sobretudo no atendimento à queixa escolar, ilustrado pela fala de uma das psicólogas do equipamento: "Eu fico só interna. Não faço visita à escola, não faço visita domiciliar porque não tenho tempo" (PARTICIPANTE DA PESQUISA 2, 2016). Vale ressaltar que a precarização do equipamento interferindo no atendimento às queixas escolares também foi encontrada na pesquisa de Marçal e Silva (2006) e Beltrame e Boarini (2013), sinalizando que essa não é uma questão específica da cidade de Salvador-Bahia.

Aliado à falta de estrutura, soma-se o fato de que a escola foi um dos lugares que mais encaminhava crianças e adolescentes para o equipamento, sendo que muitos chegavam com supostos diagnósticos, com destaque para a hiperatividade. Nas palavras de uma assistente social, "[...] as crianças já 
chegam diagnosticadas, muitos casos nem ficam" (PARTICIPANTE DA PESQUISA 3, 2015). Trata-se da medicalização da educação, fortemente presente nos depoimentos das participantes da pesquisa, que se queixaram da expectativa de oficialização do diagnóstico e prescrição de medicamentos. Sobre essa questão, Beltrame e Boarini assinalam que:

A medicação tornou-se, literalmente, o remédio para os problemas de toda ordem, seja de ordem médica ou não, e dela nos utilizamos para compreender e solucionar os conflitos produzidos socialmente, tentando, mediante intervenções voltadas para a criança em particular, resoluções para os problemas da educação, da saúde, da família e da relação entre adultos e crianças em geral. Assim, muitas condutas, como a indisciplina ou a não aprendizagem, que, a nosso juízo, evidenciam os precários resultados do sistema educacional e escolar em nossos dias, possuem uma classificação e são diagnosticadas segundo os critérios do DSM-IV ou do CID-10. Ressaltamos que o CAPSi não está excluído desse processo, ao contrário, participa de forma ativa: constitui a via para a obtenção desse diagnóstico e, em consequência, da medicação (BELTRAME; BOARINE, 2013 , p. 343).

Considerando ainda a dimensão do território, a falta de carro e o excesso de trabalho, amplia-se a dificuldade de estabelecer uma parceria profícua com as escolas, que acentua-se com o desconhecimento da escola em relação à função do equipamento que, por sua vez, não fornece nenhum tipo de retorno às escolas, reforçando a lógica da culpabilização, medicalização e exclusão. Outro fator que esteve bastante presente foi a questão dos benefícios. O CAPSi atende uma população pobre e que, no modelo atual de política pública, acaba necessitando de um diagnóstico para ter acesso a benefícios como BPC (Benefício de Prestação Continuada), passe livre e até mesmo para matricular suas/seus filhas/filhos na escola. Sobre essa questão Nikolas Rose (2013) apresenta que nos países de capitalismo periférico, as classes mais pobres, com fins de sobrevivência, têm negociado a sua inclusão social e econômica utilizando-se do estatuto biológico. Em outras palavras, tem sido negociado um diagnóstico incapacitante para a garantia de direitos que, a priori, seriam de todos e todas.

Nesse sentido, estimulados por um tipo de bem-estar calcado em critérios biomédicos e científicos, esses segmentos da população passaram a exigir 
recursos e direitos sociais com a alegação de serem prejudicados biologicamente. Depreende-se que esse tipo de inclusão refere-se ao que José Martins (1997, p. 26 e 32) denomina de "[...] inclusão precária e instável, marginal", em que a sociedade capitalista exclui para depois incluir de seu próprio modo, através de sua lógica. $\bigcirc$ autor argumenta que com a diminuição dos postos de trabalho na sociedade atual, "[...] o tempo em que o trabalhador passa a procurar trabalho começou a se tornar excessivamente longo e frequentemente o modo que encontra para ser incluído é um modo que encontra certa degradação".

Porém, essa reinclusão acontece no plano econômico, mas ela não se dá no plano social, pois incorre em prejuízos para a pessoa. As pessoas são incluídas de forma perversa no plano econômico para garantir sua sobrevivência e manter o serviço e a circulação de mercadorias. Esse modo de inclusão voltado para com pessoas com deficiência e transtornos mentais foi encontrado na pesquisa através do benefício previdenciário (especialmente o BPC) e do passe livre, já que há a necessidade de um laudo atestando deficiência física, mental, intelectual ou sensorial para que o benefício seja disponibilizado. Foi um elemento preponderante a percepção que muitas famílias procuram

214 o CAPSi para conseguir um diagnóstico para seus filhos e terem acesso aos benefícios, fator que gerou muito incômodo nas profissionais. Trata-se de fenômeno que merece maior atenção de pesquisas, ressaltando que não é objetivo da presente pesquisa julgar as famílias que operam com essa lógica, já que a mesma é estimulada no bojo das políticas de benefícios mencionadas acima, e catalisada pela precarização dos serviços públicos oferecidos à população em geral.

A intenção é frisar que, ao contrário de promover oportunidades e até direito adquirido, no dia a dia do CAPSi essa equação "um diagnóstico por um direito" acaba reafirmando o estigma e sustentando a condição de "doentes" da criança e adolescente pobres. Essa questão também foi encontrada e debatida em um estudo etnográfico realizado em um CAPS adulto pelo pesquisador Marcos Carvalho (20 14), apontando os efeitos gerados ao condicionar um direito a um laudo ou diagnóstico. Reiteramos que não se trata aqui de culpabilizar essas famílias e de defender o fim desses benefícios, já que tirá-los seria, no limite, decretar a sua morte. A intenção, ao contrário, é de pensar o direito à dignidade sequestrado pelo mesmo diagnóstico, que supostamente o garante. 
Portanto, foi possível notar que direitos sociais condicionados a um diagnóstico e escolas que cobravam diagnósticos e tratamento para alunos com problemas no processo de escolarização dos serviços de saúde foram elementos preponderantes no dia a dia da instituição. Aliados à falta de estrutura, esses elementos dificultaram bastante o atendimento à queixa escolar no equipamento. Apesar de a política pública de saúde mental no Brasil pregar uma abordagem de cuidados de cunho psicossocial, foi possível notar que, com a precarização do CAPSi, este acaba funcionando em muitos casos através de uma lógica ambulatorial, aspecto reconhecido e mesmo lamentado pelas profissionais acompanhadas na pesquisa (BRASIL, 2004; BELTRAME, BOARINI, 20131.

Levando em consideração as dificuldades supracitadas, no que tange ao atendimento à queixa escolar, percebeu-se uma tentativa por parte das profissionais de desconstruir os pseudodiagnósticos que chegavam da escola. Porém, as intervenções quase sempre se centraram na criança e sua família. Um exemplo que ilustra essa situação pôde ser visto no acolhimento de uma menina de aproximadamente 13 anos, encaminhada pela escola por apresentar um "descomportamento". Durante o atendimento, a menina relatou que "os meninos batem em mim e a professora não faz nada. Ela me puxou pela camisa e me mandou para a diretoria" (PARTICIPANTE DA PESQUISA 4, 2015). Logo após ouvir o relato da menina, a profissional que realizava o acolhimento pediu para ela sair da sala, perguntou se a mãe tinha pulso firme com os filhos e orientou:

Talvez a senhora tenha que ter um pouco mais de autoridade. Ela saber as consequências do que fez. Aqui no CAPS a gente pensa que o problema não é só da criança, há as questões da família também. A responsabilidade também é da família (PARTICIPANTE DA PESQUISA 5, 2015).

A maneira predominante que as profissionais atenderam estes casos partiu da concepção que a queixa escolar era resultado de problemas familiares ou intrínsecos aos alunos, ou seja, remetiam a fatores externos à escola. Nos momentos em que os pais ou as crianças e adolescentes falavam sobre a escola, as intervenções quase sempre se voltavam para o âmbito familiar e individual, de forma que a situação ocorrida no ambiente escolar passava despercebida ou era pouco explorada. As/os profissionais reconheceram em 
alguns momentos a precarização e as dificuldades da escola pública, porém seu viés de análise centrou-se na família e/ou na criança e adolescente. Trata-se do modelo clínico tradicional de atendimento (SOUZA, 2010), discutido e criticado à exaustão pela psicologia escolar e educacional em uma perspectiva crítica.

Destaca-se também que muitos casos de queixa escolar estão sendo encaminhados para salas de Atendimento Educacional Especializado (AEE), acompanhamento psicopedagógico e atendimento psicoterápico no CAPSi ou nos serviços de psicologia de instituições de ensino superior. É importante frisar mais uma vez: crianças e adolescentes com queixa escolar estão sendo diagnosticadas/os com transtornos mentais leves ou com deficiência intelectual. Os casos de deficiência intelectual merecem um destaque especial, pois foi relatado que as dificuldades de aprendizagem são frequentes entre eles e muitos deles têm sido tratados unicamente pela/o psiquiatra do CAPSi, cuja prática centra-se na administração de medicamentos. Muitos deles ficam até a idade adulta, correndo o risco de cronificação, de seguirem a "carreira de doente mental".

Ocorreram também muitos casos de queixa escolar, que pela falta 216 de lugares na rede para encaminhar e por não se encaixarem na política do CAPSi, têm ficado no que as/os profissionais chamam de "limbo", ou seja, ficam largados na rede sem um lugar para serem atendidos, evidenciando mais uma vez a precarização das políticas públicas.

Por fim, cumpre reconhecer que foi encontrada, embora de maneira mais incipiente, a tentativa de desconstrução da queixa já no acolhimento, modo de atendimento que respeita a orientação do próprio Ministério da Saúde no cuidado à saúde mental infanto-juvenil. Ele orienta que toda demanda encaminhada ao CAPSi deve ser acolhida, ouvida e respondida, mesmo que não seja necessariamente atendida, colocando como possibilidade de tratamento a desconstrução da demanda. Nela, realizam-se intervenções junto a outras instituições, como a escola, visando à construção de uma rede intersetorial de atendimento (BRASIL, 2005).

Na pesquisa, essa maneira de atendimento foi encontrada quando as/os profissionais procuravam questionar a queixa escolar e os pseudodiagnósticos dados pela escola, já no próprio acolhimento. Um exemplo sobre essa possibilidade de atuação pôde ser encontrado na fala de uma das assistentes 
sociais do equipamento, quando comenta que "[...] o acolhimento seria o lugar para desconstruir essas demanda e que os profissionais não fazem isso, preferem fazer grupo ou terapia" (PARTICIPANTE DA PESQUISA 6, 2015).

\section{Análise das entrevistas}

As entrevistas objetivaram compreender qual a perspectiva de profissionais sobre a queixa escolar encaminhada para o CAPSi. Foram entrevistadas três profissionais do equipamento pesquisado que atendem a queixa escolar. A escolha aconteceu de acordo com os preceitos da etnografia, baseados no contato com o pesquisador e na confiança obtida durante o processo (ROCKWELL, 1988).

As entrevistadas se queixaram fortemente da falta de estrutura para fazer o seu trabalho, evidenciando a predominância desse aspecto na pesquisa. Elas também relataram que a formação na graduação não as preparou para a atuação na política de Saúde Mental na infância e adolescência, implicando em que as mesmas tiveram que aprender como proceder nesses casos a partir da própria prática ou em cursos de pós-graduação, como pode ser evidenciado nas seguintes falas:

Psicologia do desenvolvimento e (pausa) psicopatologia também. Mas, não tem muita, realmente você perguntando isso me faz ver que não tem muito, acho que falta muito uma formação nessa área. Porque é uma área que tem suas especificidades, a infância e adolescência também. Então, eu acho que falta muito na formação de psicologia. $\bigcirc$ que eu me lembro é desenvolvimento um, dois e três e psicopatologia que aí eu entrei em contato com o autismo, por exemplo. Mas, eu acho que falta muito na formação (ENTREVISTADA 1, 2016).

Na época, na minha formação, eu me formei pela UFBA, o que vigorava era psicologia clínica, psicologia do trabalho, pouco se falava sobre psicologia escolar, pouco se falava sobre psicologia hospitalar. Era mais clínica e trabalho (ENTREVISTADA 2, 2016 ).

Apenas uma delas relatou ter feito uma pós-graduação na área de educação. Esse aspecto coaduna com a crítica que Souza e Braga (2014) fazem à formação profissional nos cursos de saúde, que no geral, dedica-se pouco às questões educacionais, predominando o modelo clínico tradicional. 
A queixa escolar em um CAPSi de Salvador-Bahia: uma análise a partir da psicologia escolar crítica

A própria política de saúde mental infantil pouco fala da escola, das políticas educacionais e de como elas, historicamente, têm produzido fracasso escolar. Daí que Souza e Braga afirmam:

Embora se busquem articulações por meio de políticas intersetoriais, no que tange ao atendimento à infância e à adolescência, a questão da escolarização visivelmente presente nos índices de encaminhamento apresentados pelos diversos levantamentos realizados, não foram, ainda, suficientes para que essa realidade fosse considerada no interior de políticas de saúde pública (SOUZA; BRAGA, 2014, p. 55).

A compreensão das políticas educacionais como historicamente produtora de fracasso escolar, esteve presente apenas na fala de uma das entrevistadas, que fez uma pós-graduação na área de educação, como pode ser visto no seguinte trecho:

Eu acho que a escola precisava ser revista. Aí é que eu acho que é muito amplo isso que eu estou falando. Eu acho que a quantidade de alunos, o tanto que o professor tem que trabalhar, a falta de investimento do governo na educação [...] aí tem uma série de outras coisas que eu não acho que o menino tem uma dificuldade de..., às vezes a questão familiar pode estar interferindo também, como é que estava a família dele quando ele estava sendo alfabetizado, tem várias coisas que precisavam ser vistas e que a gente fica preso sem saber como intervir nisso (ENTREVISTADA 3, 2016).

A partir das entrevistas, foi possível notar que existe uma tentativa de superação do discurso medicalizante e da visão individualizante sobre o aluno e a queixa escolar. Houve uma preocupação também com os pseudodiagnósticos recebidos pelas crianças e adolescentes por parte da escola, bem como com o uso de medicação e com o diagnóstico psiquiátrico na infância. Porém, a visão parece recair para a família ou para as deficiências intelectuais e transtornos leves, apontando uma contradição no entendimento. Nos dizeres de uma das entrevistadas:

Só que quando a gente acolhe uma criança e a família, a gente não tenta reduzir isso. A gente tenta ver, ter uma visão maior de como está funcionando a família, como é que está a criança. A queixa escolar é uma das coisas, às vezes é o que mais aparece. 
A dificuldade de aprendizagem ou então a agitação na escola e aí vem relatório da escola se queixando que a criança não consegue prestar atenção. E aí a escola às vezes pede um diagnóstico do CAPS e medicação também. Então, eu já vi chegar muito com essa demanda da escola, mas a gente sempre tenta ver a criança de uma forma mais ampla. A gente nunca foca só na queixa escolar (ENTREVISTADA 1, 2016).

Outro aspecto também comum no entendimento sobre a queixa escolar nas entrevistadas foi de que o fracasso escolar seria causado por uma questão técnica do professor ou da escola. Segundo uma das entrevistadas, o problema da educação brasileira é " [...] que falta técnica, eu acho que é tudo desamarrado" (ENTREVISTADA 2, 2016). Essa concepção está intrinsicamente ligada ao que Souza (2006) denomina de mito da incompetência docente. A autora argumenta que diante das críticas à educação brasileira realizadas, sobretudo, a partir da década de 1980, as explicações que até então individualizavam o fracasso escolar no aluno ou em sua família pobre voltaram-se para a culpabilização de professores e profissionais da instituição escolar.

Porém, essa escola e as políticas educacionais não passaram a ser problematizadas com esse discurso. Ao contrário, permaneceu a lógica individualizante, agora focalizando a suposta falta de competência técnica ou de compromisso do professor. Alimentando essa lógica, começou a se desenvolver um mercado de formação continuada para professores, culpabilizando o professor pela baixa performance do sistema educacional e gerando o enfraquecimento das já difíceis relações entre eles. Trata-se, novamente, de um olhar individualizante e culpabilizante sobre o fracasso escolar.

\section{Considerações finais}

A partir da análise dos prontuários, foi possivel encontrar que as queixas escolares estão presentes na maioria dos casos atendidos no CAPSi pesquisado. $\bigcirc$ perfil majoritário é composto por alunos nos primeiros anos de apropriação de leitura e escrita, indicando que as políticas educacionais relativas ao letramento podem estar presentes nesses encaminhamentos. Foi revelado um número relevante de diagnósticos de Retardo Mental e TDAH, diagnósticos que historicamente têm sido associados à medicalização de crianças e adolescentes das classes mais pobres da sociedade. 
Em conjunto com os relatos ampliados, as três entrevistas indicam que a maneira de entender e atender a queixa escolar hegemonicamente parte de uma perspectiva individualizante e medicalizante, advindo do modelo clínico tradicional. Porém, existe uma tentativa de superação, sobretudo no que tange aos efeitos do diagnóstico e ao uso da medicação. Foi perceptível também a tendência de naturalizar a escola, sobretudo a pública, não sendo reconhecida como historicamente participante na produção do fracasso escolar. Destaca-se ainda a presença da desconstrução da demanda, suscitando a possibilidade de novos modelos de atuação à queixa escolar nesses equipamentos.

A precarização do CAPSi e da rede de serviços públicos também foi encontrada como um elemento que dificulta o atendimento no equipamento, sobretudo no que tange às queixas escolares. Disso resulta um funcionamento que parte de uma lógica ambulatorial, diferindo do caráter psicossocial preconizado pela política pública nacional de saúde mental. Outras questões que também apareceram como desafios enfrentados no atendimento foram a medicalização da educação, resultando em alto número de alunos encaminhados pela escola com pseudodiagnósticos, e as famílias que procuravam o equipamento na busca de um laudo para ter acesso a benefícios concedidos 220 pelo governo, efeito da política de condicionar um diagnóstico para ter acesso a direitos.

Assim, os resultados sugerem a necessidade de inserir uma discussão maior nos cursos de formação na área de saúde, tematizando a medicalização da educação e da pobreza, a política educacional e a escola como historicamente participantes na produção do fracasso escolar. Seria importante também promover discussões sobre esses pontos nas formações continuadas, realizadas pelas secretarias municipais e estaduais de saúde.

Devido às limitações de tempo, não foi possível, nesse estudo, ouvir as crianças e adolescentes com queixa escolar no CAPSi, bem como seus familiares. Sugerem-se pesquisas com esses públicos para mostrar os efeitos do encaminhamento e atendimento de queixas escolares no âmbito da saúde mental. Além disso, é importante investigar como a queixa escolar é acolhida e atendida em outros CAPSi, já que as pesquisas sobre a temática são escassas. Investigar se em outros contextos, com territórios menores, o equipamento consegue estabelecer uma relação de parceria com as escolas e realizar trabaIhos, como o matriciamento, por exemplo. 
Portanto, a partir do que foi exposto, espera-se que esse trabalho possa contribuir com o atendimento à queixa escolar nos serviços de saúde mental que a reconheça como fruto de múltiplas determinações e leve em consideração a complexidade do fenômeno. Tem-se a expectativa de que as reflexões aqui propostas auxiliem na construção de práticas que façam frente aos processos de medicalização, contribuindo para uma educação e saúde mental que acolham as diferenças e potencialidades.

\section{Notas}

1 Autores questionam a existência do chamado retardo mental leve. Argumentam que, historicamente, esse diagnóstico relaciona-se com o higienismo, a eugenia e o pensamento segregacionista. Ele tem servido para os processos de exclusão e rotulação, criando manifestações que se expressam como causa e não efeito das situações de fracasso escolar. Recomenda-se a leitura de Kalmus (2000) e Gould (2014).

2 No caso do TDAH, pesquisadoras/es de diversas áreas têm criticado e contestado a existência desse transtorno. Para o aprofundamento dessas críticas, sugere-se a leitura de Lima (2005; $2016)$ e Viégas e Oliveira (2014)l.

\section{Referências}

BELTRAME, Marina Maria; BOARINI, Maria Lúcia. Saúde mental e infância: reflexões sobre a demanda escolar de um CAPSi. Psicologia, Ciência e Profissão, Brasília, v. 33, n. 2, p. 334-349, 2013. Disponível em: http://www.scielo.br/scielo.php? script=sci_arttext\&pid=S $141498932013000200007 \&$ lng=en\&nrm=iso. Acesso em: 12 ago. 2017.

BORDINI, Daniela; GADELHA, Ary; PAULA, Cristiane Silvestre; BRESSAN, Rodrigo Affonseca. Encaminhamento escolar de crianças e adolescentes para o CAPSi: o peso dos encaminhamentos incorretos. Revista Brasileira de Psiquiatria, São Paulo, v. 34, n. 4, p. 493-496, dez. 2012. Disponível em: <http://www.scielo.br/scielo.php?script=sci_arttext\&pid=S15 164446201200040001 8\&lng=en\&nrm=iso>. Acesso em: 6 jul. 2017.

BRAGA, Júlia Dile Medeiros e Albuquerque de Moraes; JESUS, Dione Paula de. Matriciamento em Saúde Mental na escola. $1^{\circ}$ Congresso Brasileiro de Centros de Atenção Psicossocial Infanto-Juvenil, 2013. Rio de Janeiro. Anais... Rio de Janeiro, Universidade Estadual do Rio de Janeiro: 2013. Disponível em: <http://www.congressobrasileirodecapsi.com.br>. Acesso em: 9 jul. 2017.

BRASIL. Saúde mental no SUS: os centros de atenção psicossocial. Brasília: Ministério da Saúde, Secretaria de Atenção à Saúde, Departamento de Ações Programáticas Estratégicas, 2004. 
A queixa escolar em um CAPSi de Salvador-Bahia: uma análise a partir da psicologia escolar crítica

Caminhos para uma política de saúde mental infanto-juvenil. Brasília: Ministério da Saúde, Secretaria de Atenção à Saúde, Departamento de Ações Programáticas Estratégicas, 2005.

Lei $\mathbf{n}^{\circ}$ 10.216, de 6 de abril de 2001. Dispõe sobre a proteção e os direitos das pessoas portadoras de transtornos mentais e redireciona o modelo assistencial em saúde mental.Disponível em: http://hpm.org.br/wp-content/uploads/2014/09/lei-no-10.216de-6-de-abril-de-2001.pdf. Acesso em: 18 jul. 2017.

Portaria n ${ }^{\circ}$ 336, 19 de fevereiro de 2002. Dispõe sobre a proteção e os direitos das pessoas portadoras de transtornos mentais e redireciona o modelo assistencial em saúde mental. Disponível em: http://bvsms.saude.gov.br/bvs/saudelegis/gm/2002/ prt0336_19_02_2002.html. Acesso em: 10 ago. 2017

CARVAlHO, Marcos. Dilemas na/da Reforma Psiquiátrica: notas etnográficas sobre o cotidiano de um Centro de Atenção Psicossocial. In: FERREIRA, Jaqueline; FLEISCHER, Soraya (Org.). Etnografias em serviços de saúde. Rio de Janeiro: Garamond, 2014.

COUTO, Maria Cristina Ventura. Política de saúde mental para crianças e adolescentes: especificidades e desafios da experiência brasileira (2001-2010). 2012. 178f. Tese (Doutorado em Saúde Mental) - Programa de Pós-Graduação em Psiquiatria e Saúde Mental, do Instituto de Psiquiatria da Universidade Federal do Rio de Janeiro, Rio de Janeiro, 2012.

CABRAL, Estela; SAWAYA, Sandra Maria. Concepções e atuação profissional diante das queixas escolares: os psicólogos nos serviços públicos de saúde. Estudos de Psicologia, Natal, v. 6, n. 2, 2001 . p. 143-155. Disponível em: http://www.scielo.br/pdf/epsic/ von2/7269. Acesso em: 18 jul. 2017.

COLLARES, Cecília Azevedo Lima; MOYSÉS, Maria Aparecida Affonso. A educação na era dos transtornos. In: VIÉGAS, Lygia de Sousa; RIBEIRO, Maria Izabel Souza; OIIVEIRA, Elaine Cristina de; TELES, Liliane da Luz (Org.). Medicalização da educação e da sociedade: ciência ou mito? Salvador: EDUFBA, 2014.

ENTREVISTADA 1. Entrevista. Salvador (Bahia), 18 ago. 2016.

ENTREVISTADA 2. Entrevista. Salvador (Bahia), 15 ago. 2016.

ENTREVISTADA 3. Entrevista. Salvador (Bahia), 14 set. 2016.

FÓRUM SOBRE MEDICALIZAÇÃO DA EDUCAÇÃO E DA SOCIEDADE. Recomendações de práticas não medicalizantes para profissionais e serviços de educação e saúde. 2 ed. São Paulo: Conselho Federal de Psicologia, 2013.

FÓRUM SOBRE MEDICALIZAÇÃO DA EDUCAÇÃO E DA SOCIEDADE. Carta do IV Seminário Internacional A Educação Medicalizada: desver o mundo, perturbar os sentidos. 
Salvador, 2015. Disponível em: http://seminario4.medicalizacao.org.br/carta-do-iv-seminario-internacional-a-educacaomedicalizada-desver-o-mundo-perturbar-os-sentidos/. Acesso em: 14 dez. 2016.

GAUDENZI, Paula; ORTEGA, Francisco. O estatuto da medicalização e as interpretações de Ivan Illich e Michel Foucault como ferramentas conceituais para o estudo da desmedicalização. Interface, Botucatu, v. 16, n. 40, mar. 2012. p. 21-34. Disponível em: http://www. scielo.br/scielo.php?script=sci_arttext\&pid=S $1414-32832012000100003 \&$ ng =pt\&nrm= iso. Acesso em: 16 jul. 2017.

GONZAGA, Amarildo Menezes. A pesquisa em educação: Um desenho metodológico centrado na abordagem qualitativa. In: PIMENTA, Selma Garrido; GHEDIN, Evandro; FRANCO, Maria Amélia Santoro (Org.). Pesquisa em educação: alternativas investigativas com objetos complexos. São Paulo: Loyola, 2006.

GOULD, Stephen Jay. A falsa medida do homem. São Paulo: Editora WMF; Martins Fontes, 2014.

ILLICH, Ivan. Sociedade sem escolas. Petrópolis: Vozes, 1985.

1975.

A expropriação da saúde: nêmesis da medicina. Rio de Janeiro: Nova Fronteira,

KALMUS, Jaqueline. A produção da deficiência mental leve. 2000. 91f. Dissertação (Mestrado em Psicologia Escolar e do Desenvolvimento Humano) - Programa de PósGraduação em Psicologia Escolar e do Desenvolvimento Humano, Universidade de São Paulo, São Paulo, 2000.

KUPFER, Maria Cristina Machado. $\bigcirc$ Que Toca à/a Psicologia Escolar. In: MACHADO, Adriana Marcondes; SOUZA, Marilene Proença Rebello de (Org.). Psicologia Escolar: em busca de novos rumos. São Paulo: Casa do Psicólogo, 2010.

LIMA, Rossano Cabral. Somos todos desatentos? $\bigcirc$ TDA/H e a construção de bioidentidades. Rio de Janeiro: Relume Dumará, 2005.

Psiquiatria infantil, medicalização e a Síndrome da Criança Normal. In: Comissão de Psicologia e Educação do CRP-RJ (Org.). Conversações em Psicologia e Educação. Rio de Janeiro: Conselho Regional de Psicologia, 2016.

LÜDKE, Menga; ANDRÉ, Marli Dalmazo Afonso de. Pesquisa em educação: abordagens qualitativas. São Paulo: EPU, 1986.

MACEDO, Roberto Sidnei. A etnopesquisa crítica e multirreferencial nas ciências humanas e na educação. Salvador: EDUFBA, 2000. 
A queixa escolar em um CAPSi de Salvador-Bahia: uma análise a partir da psicologia escolar crítica

MACHADO, Adriana Marcondes. Avaliação psicológica e as relações institucionais. Conselho Federal de Psicologia (Org). Ano da avaliação psicológica - Textos geradores. Brasilia: Conselho Federal de Psicologia, 2011.

MYNAIO, Maria Cecília de Souza. O desafio do conhecimento: pesquisa qualitativa em saúde. São Paulo: Hucitec, 2014.

MARÇAL, Viviane Prado Buiatti; SILVA, Silvia Maria Cintra da. A queixa escolar nos ambulatórios públicos de saúde mental: práticas e concepções. Psicologia Escolar e Educacional, Campinas, v. 10, n. 1, jan./jul. 2006. Disponível em: http://www.scielo.br/scielo. php?pid=S1 41 3-855720060001000 1 1\&script=sci_abstract\&tIng=pt. Acesso em: 19 jul. 2017

MARTINS, José de Souza. Exclusão social e a nova desigualdade social. São Paulo: Paulus, 1997.

PARTICIPANTE DA PESQUISA 1. Entrevista. Salvador (Bahia), 23 nov. 2015.

PARTICIPANTE DA PESQUISA 2. Entrevista. Salvador (Bahia), 15 abr. 2016.

PARTICIPANTE DA PESQUISA 3. Entrevista. Salvador (Bahia), 10 nov. 2015.

PARTICIPANTE DA PESQUISA 4. Entrevista. Salvador (Bahia), 16 nov. 2015.

224 PARTICIPANTE DA PESQUISA 5. Entrevista. Salvador (Bahia), 16 nov. 2015.

PARTICIPANTE DA PESQUISA 6. Entrevista. Salvador (Bahia), 4 dez. 2015.

PATTO, Maria Helena Souza. Psicologia e ideologia: uma introdução crítica à psicologia escolar. São Paulo: T. A. Queiroz, 1984.

A produção do fracasso escolar: histórias de submissão e rebeldia. São Paulo: Casa do Psicólogo, 1999.

ROCKWELL, Elsie. Reflexiones sobre el proceso etnográfico (1982-1985). México, D.F: XII, 1988.

ROSE, Nikolas. A política da própria vida: biomedicina, poder e subjetividade no século XXI. São Paulo: Paulus, 2013.

SOUZA, Beatriz de Paula. Funcionamentos escolares e a produção de fracasso escolar e sofrimento. In: SOUZA, Beatriz de Paula (Org). Orientação à queixa escolar. São Paulo: Casa do Psicólogo, 2007.

Apresentando a orientação à queixa escolar. In: SOUZA, Beatriz de Paula (Org).

Orientação à queixa escolar. São Paulo: Casa do Psicólogo, 2007. 
SOUZA, Denise Trento Rebello de. Formação continuada de professores e fracasso escolar: problematizando o argumento da incompetência. Educação e Pesquisa, São Paulo, v. 32, n. 3, dez. 2006. p. 477-492. Disponivel em: http://www.scielo.br/scielo.php?script=sci_ arttext\&pid=\$1 517-97022006000300004\&lng=en\&nrm=iso. Acesso em: 30 jul. 2017.

SOUZA, Marilene Proença Rebello de. A queixa escolar e o predomínio de uma visão de mundo. In: MACHADO, Adriana Marcondes; SOUZA, Marilene Proença Rebello de (Org.).

Psicologia escolar: em busca de novos rumos. São Paulo: Casa do Psicólogo, 2010.

SOUZA, Marilene Proença Rebello de; BRAGA, Sabrina Gasparetti. Da educação para a saúde: trajetória dos encaminhamentos escolares de 1989 à 2005. In: DIAS, Elaine T. Mas; AZEVEDO, Liliana Pereira Lima (Org.). Psicologia escolar e educacional: percursos, saberes e intervenções. Jundiaí: Paco Editorial, 2014.

THIOLLENT, Michel Jean Marie. Crítica metodológica, investigação social e enquete operária. São Paulo: Editora Polis, 1980.

VIÉGAS, Lygia de Sousa. Reflexões sobre a pesquisa etnográfica em Psicologia e Educação. Diálogos Possíveis, Salvador, v. 1, p. 101-123, 2007.

- Direitos Humanos e políticas públicas medicalizantes de Educação e Saúde: uma análise a partir da psicologia escolar e educacional. In: VIÉGAS; Lygia de Sousa; RIBEIRO; Maria Izabel Souza; OIIVEIRA, Elaine Cristina de; TELES, Liliane da Luz (Org.). Medicalização da educação e da sociedade: ciência ou mito? Salvador: EDUFBA, 2014.

Atuação do psicólogo na rede pública de educação da Bahia. In: SOUZA, Marilene Proença Rebello de; SIIVA, Silvia Maria Cintra da; YAMAMOTO, Kátia (Org.). Atuação do psicólogo na Educação Básica: concepções, práticas e desafios. Uberlândia: EDUFU, $2014 a$.

VIÉGAS, Lygia de Sousa; FREIRE, Klessyo do Espirito Santo. O debate sobre medicalização na psicologia escolar e educacional em uma perspectiva crítica: aspectos históricos: In: DANTAS, Jurema Barros (Org.). A infância medicalizada: discursos, práticas e saberes para o enfrentamento da medicalização da vida. Curitiba: Editora CRV, 2015.

VIÉGAS, Lygia de Sousa; OLIVEIRA, Ariane Rocha Felício de. TDAH: Conceitos vagos, existência duvidosa. Nuances: Estudos sobre Educação, Presidente Prudente, v. 25, n. 1, p. 39-58, jan./abr. 2014. Disponível em: http://revista.fct.unesp.br/index.php/Nuances/ article/view/2736/2517. Acesso em: 29 jul. 2016.

Prof. Ms. Klessyo do Espirito Santo Freire Universidade Federal da Bahia 
Faculdade de Educação Grupo de Pesquisa Educação, Política, Indivíduo e Sociedade: Leituras a partir da Pedagogia, da Psicologia e da Filosofia E-mail | klessyo@gmail.com

Profa. Dra. Lygia de Sousa Viégas Universidade Federal da Bahia Faculdade de Educação Programa de Pós-Graduação em Educação Grupo de Pesquisa Educação, Política, Indivíduo e Sociedade: Leituras a partir da Pedagogia, da Psicologia e da Filosofia E-mail | lyosviegas@gmail.com Recebido 10 out. 2017 Aceito 20 nov. 2017 